\title{
New Antibacterial Therapeutics and Strategies
}

\author{
ANNA KUREK, ANNA M. GRUDNIAK, ANNA KRACZKIEWICZ-DOWJAT \\ and KRYSTYNA I. WOLSKA* \\ Department of Bacterial Genetics, Institute of Microbiology, Faculty of Biology \\ University of Warsaw, Warsaw, Poland
}

Received 13 January 2011, accepted January 2011

\begin{abstract}
Studies on new antibacterial therapeutics and strategies are currently being conducted in many microbiological, pharmaceutical and biochemical laboratories. The antibacterial activity of plant-derived compounds as well as silver and gold nanoparticles is the subject of this minireview. The application of photodynamic therapy is also discussed.
\end{abstract}

K e y words: nanoparticles, new antimicrobials, phototherapy, plant compounds

\section{Introduction}

The growing antibiotic resistance of pathogenic bacterial species is a serious problem for public health. It can be assumed, that although the bulk of traditional antibiotics can still manage drug-resistant bacteria, many commonly used antibiotics are no longer effective (Levy, 1998; Wright, 2010). This situation is aggravated by a decline in the development of new antibiotics, so recently few substances have appeared in the market (Donadio et al., 2010; Högberg et al., 2010). In view of above, the growing interest in the studies aimed at developing new antibacterial therapeutics and strategies is very important not only from medical point of view but also for agriculture and animal breeding (Myles, 2003). The list of such therapeutics is long with stress on the use of bacteriophages as antibacterial agents (Chibani-Chennoufi et al., 2004; Górski et al., 2009). Many papers cover this problem so it will not be the subject of our publication. The present article describes the antibacterial potency and application of plant-derived compounds, nanoparticles and also the very promising photodynamic therapy.

\section{Plant-derived compounds}

Plant-derived compounds of therapeutic value are mostly the secondary plant metabolites (Cowan, 1999). Antibacterial phytochemicals are divided in several categories, this article describe two of them - terpenes and phenolics including polyphenols. As a matter of fact, these compounds cannot be considered a new group of antimicrobials because people have applied plants and plant extract for medical purposes for centuries (Rios and Recio, 2005).

Terpenes. Terpenes, also referred to as isoprenoids, are based on an isoprene structure with general chemical formula $\mathrm{C}_{10} \mathrm{H}_{16}$ and are biosynthesized from the same basic units, isopentenyl diphosphate, IPP, and its isomer dimethylallyl diphophate, DMAPP (Fig. 1A). Their derivatives containing additional elements, usually oxygen, are called terpenoids. These compounds have a lot of biological functions and are applied as pharmaceuticals, fragrances, colorants. Terpenes constitute a very diverse group of compounds isolated not only from higher plants but also from microorganisms (Sacchettini and Poulter, 1997). Successful approaches in engineering Escherichia coli towards biosynthesis of functional isoprenoids were recently described (Harada and Misawa, 2009).

Of special interest are two pentacyclic triterpenoids oleanolic acid (OA) and ursolic acid (UA) and their derivatives containing sugar moieties - glucosides and glucuronides. The chemical formulas of $\mathrm{OA} / \mathrm{UA}$ are presented in Figure 1B. The antibacterial activity of these compounds was recently reviewed (Wolska et al., 2010a). The data described in many papers are contrasting and indicate either a strong or weak

* Corresponding author: K.I. Wolska, Department of Bacterial Genetics, Institute of Microbiology, University of Warsaw, Miecznikowa 1, 02-096 Warsaw, Poland; phone: (+48) 22 55-41-302; fax: (+48) 225541 402; e-mail: izabelaw@biol.uw.edu.pl 

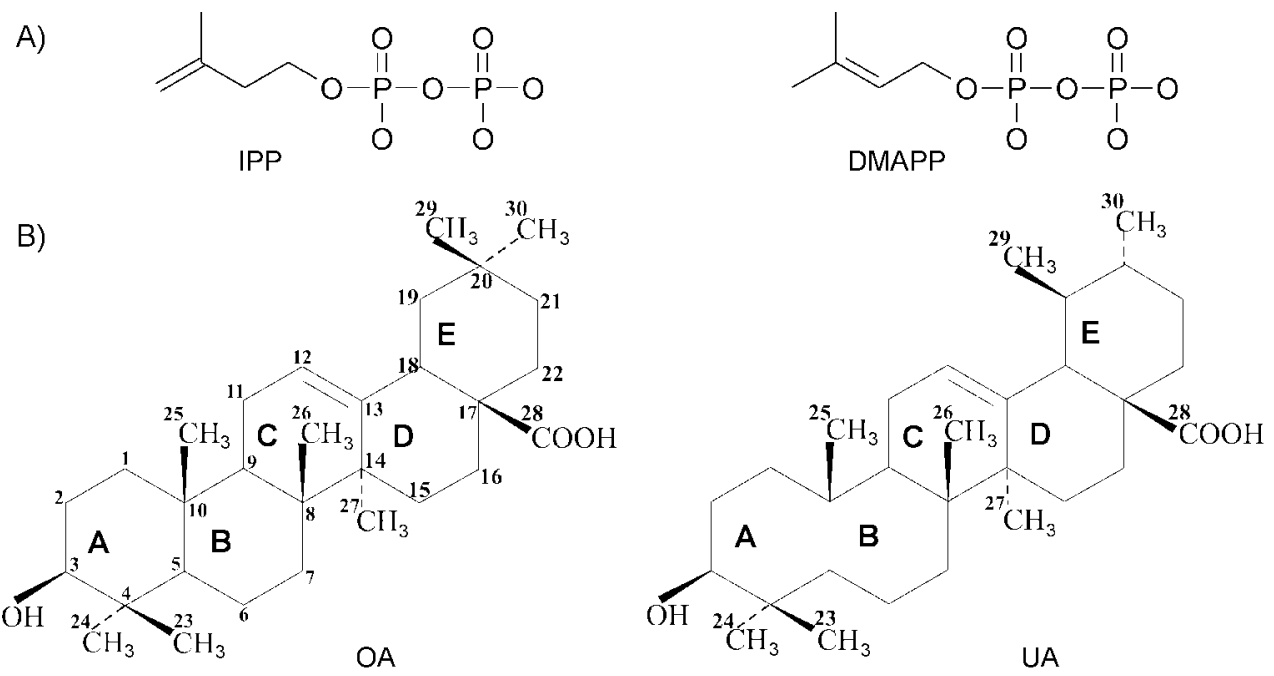

Fig. 1. Chemical formula of IPP and DMAPP (A) and OA and UA (B)

antibacterial effect of OA and UA which likely results from the method of compound purification and the bacterial strain used. A relatively small number of studies has been performed to investigate the basis of OA/UA antibacterial activity. It has been shown that both acids affected peptidoglycan metabolism in Listeria monocytogenes (Kurek et al., 2010), oleanolic acid cyclodextrins inhibited insoluble glucan synthesis by Streptococcus mutans (Kozai et al., 1999) and oleane-type triterpenoid, glycyrrhizin acted as a potent E. coli heat-labile enterotoxin inhibitor (Chen et al., 2009). In turn Ren and coworkers (2005) using microaaray techniques demonstrated that UA caused differential gene expression in E. coli and inhibited biofilm formation in several bacterial species. Recently Ge and coworkers (2010) proved the synergistic interactions of OA in combination with isoniazid, rifampicin or ethanbutol against Mycobacterium tuberculosis. The third pentacyclic triterpenoid with similar chemical structure - betulic acid (BA) is inactive against a large number of Gram-positive and Gram-negative bacteria. This result illustrates the strong structurefunction influence of the antibacterial potential of terpenes (Fontanay et al., 2008; Wansi et al., 2010).

Other terpenes or terpenoids, such as monoterpenes and sesquiterpenes and their derivatives, also display antimicrobial activity (Ahmed et al., 1993; Amaral et al., 1998; Habtermariam et al., 1993). Many publications describe the antibacterial potential of diterpenoids. It was demonstrated that six diterpenoids isolated from the bark of Podocarpus nagi, of which the most abundant compound was totarol, exhibited potent bactericidal activity against Gram-positive bacteria: Propionobacterium acnes, S. mutans and Staphylococcus aureus (Kubo et al., 1992). Naturally occurring diterpenoids with a dehydroabietane skeleton are highly bioactive (Savluchinske-Feio et al., 2006) e.g. isopimaric acid extracted from immature cones of Pinus nigra inhibited the growth of multidrug-resistant and methicillinresistant Staphylococcus aureus - MRSA (Smith et al., 2005). Antibacterial activity of diterpenoids isolated from hairy roots of Salvia sclarea L was also studied. The results showed that abietane diterpenoids: salvisipone, aethopinone, 1-oxoaethopinone and ferrugiol were bacteriostatic as well as bacteriocidal for cultures of $S$. aureus and S. epidermidis but not for the Gram-negative species, E. coli and Pseudomonas aeruginosa (Kuźma et al., 2007). Salvipisione and aethiopinone expressed staphylococcal anti-biofilm activity, the reduction in the number of live biofilm cells and changes of biofilm morphology were observed. Both diterpenoids showed synergy with several classes of antibiotics, in case of $\beta$-lactams this phenomenon was due to the probable alternation of cell surface hydrophobicity and cell envelopes permeability (Walencka et al., 2007). It was also demonstrated that diterpenes inhibited the growth of M. tuberculosis (Copp and Pearce, 2007) and recently the Chinese group showed that diterpenes isolated from the genus Scutellaria possessed the substantial antimicrobial and antiviral activities (Shang et al., 2010).

Phenolics and polyphenols. Phenolics and polyphenols constitute a very large group of chemical compounds. Simple phenols consist of a single substituted phenolic ring, flavones and their derivatives - flavanoids and flavanols are phenolic structures containing one carbonyl group, while quinones contain two carbonyl groups. Tannins are polymeric phenolic substances and coumarins are phenolic compounds made of fused benzene and pyrone rings (Cowan, 1999). The chemical formulas of exemplary phenolic compounds are shown in Figure 2.

The simple phenol, caffeic acid isolated from perennial thorny shrub, Paliurus spina-christi was 
A)<smiles>Oc1cc(O)c2c(c1)OC(c1cccc(O)c1O)C(O)C2</smiles>

B)<smiles>O=C1c2ccccc2C(=O)c2ccccc21</smiles>

C)<smiles>Oc1cc(O)c2c(c1)OC(c1cccc(O)c1O)C(O)C2</smiles>

Fig. 2. Chemical formulas of exemplary phenolic compounds with antibacterial activity. Catechin (A), Antraquinone (B), Tannin (C)

effective against Gram-positive bacterial species (Brantner et al., 1996). p-guanidinethyl and its simple parent phenols were active against $S$. aureus; the simple phenolic species showed lower activity that their calixarene analogues (Mourer et al., 2009). Other groups demonstrated that more highly oxidized phenols were also more active probably due to their ability to oxidize of sulfhydryl groups in proteins (Urs and Dunleavy, 1975; Mason and Wasserman, 1987).

Flavones and their derivatives, flavonoids and flavonols, due to their extremely large amount of biological properties, including the antibacterial activity, are placed among the most attractive plant derivatives enriching the current therapy options (Cazarolli et al., 2008). These compounds can form complexes with cell wall and also disrupt bacterial envelopes (Tsuchiya et al., 1996; Nakayama et al., 2000). Of special interest are catechins, the subgroup of flavonoids present in the oolong green teas which beneficial effect on human health is well known (Cabrera et al., 2006). These compounds are active against food-borne pathogenic bacteria and therefore exert the beneficial effect in gastrointestinal diseases (Friedman, 2007; Dryden et al., 2006; Koo and Cho, 2004). It was shown that catechins inhibited in vitro the growth of several bacterial species such as Vibrio cholerae, S. mutans and Shigella spp. (Borris, 1996; Sakanaka et al., 1992; Vijaya et al., 1995). Inactivation of specific bacterial enzymes, $V$. cholerae toxin and glucosyltransferases in S. mutans, was also reported (Borris, 1996; Nakahara et al., 1993). Chrysin, another flavonoid abundant in propolis, also displays substantial antimicrobial activity, preferentially against Gram-positive species, e.g. Streptococcus sobrinus, Enterococcus faecalis and Micrococcus luteus (Uzel et al., 2005). Its activity against certain oral pathogens, such as Peptostreptococcus anaerobius, Peptostreptococcus micros and Lactobacillus acidophilus creates the possibility of propolis application in the treatment of oral cavity diseases (Koru et al., 2007). Recently novel C(7) modified chrysin was synthesized. This modification was deliberately designed in order to enhance the anti- bacterial effect. The biological assays indicated that this compound is a potent inhibitor of beta-ketoacyl-acyl carrier protein synthetase $(\mathrm{FabH})$ in E. coli (Suresh Babu et al., 2006; Li et al., 2009).

A number of papers are concerned with the antibacterial activity of quinones. This activity is based on their high chemical reactivity inactivating the chemical compounds, mainly proteins. Surfaceexposed bacterial adhesins, cell wall polypeptides and membrane bound enzymes are their probable targets (Cowan, 1999; Koyama, 2006). Because the redoxpotential of these compounds was so essential to their activity, electrochemical techniques along with biochemical and medical knowledge were successfully combined to design and develop therapeutically efficient derivatives (Hillard et al., 2008). It should be also mentioned that quinones are strong poisons for bacterial type II topoisomerases - gyrase and TopoIV (Pommier et al., 2010). Potent antibacterial activity is attributed to the anthraquinones. It was demonstrated that anthraquinone isolated from Cassia italica is bacteriostatic for Bacillus antracis, Corynebacterium pseudodiphtericum and P. aeruginosa (Kazumi et al., 1994), in turn hypericin and hyperforin isolated from Hypericium perforatum (St. John's wort) were active against Gram-positive species - S. aureus, S. epidermidis, E. faecalis and Bacillus subtilis (Males et al., 2006; Saddiqe et al., 2010). Recently it was shown that the antibacterial activity of anthraquinone derivatives from Heterophyllaea postulata against $S$. aureus involved an increase in the level of superoxide anion and singlet molecular oxygen (Comini et al., 2010). The antimycobacterial activity of quinones was also described (Copp and Pearce, 2007).

Tannins are divided in two groups - hydrolysable (derivatives of gallic acid) and condensed, also called proanthocyanidins (derived from flavonoid monomers). Among the various health beneficial activities of tannins their antimicrobial activity is often referred to. These compounds are characterized by strong antiperoxidation properties which may be responsible for the inactivation of microbial adhesions, enzymes and 
cell envelope transport proteins (Okuda, 2005). The antioxidation activity of tannins is based on their ability to scavenge free radicals, to chelate metals and to inhibit of prooxidative enzymes and lipid peroxidation (Koleckar et al., 2008). It was well documented that tannins inhibited the growth of aquatic and foodborne bacteria, so they can be used in food processing to increase the storage time of certain foods (Chung et al., 1998). Tannins, especially proanthocyanins, inhibit the growth of uropathogenic E. coli (Cimolai and Cimolai, 2007), S. mutans (de la Iglesia et al., 2010) as well as ruminal bacteria. For the latter it was documented that condensed tannin (sainfoin) inhibited the growth and protease activity of Butyrivibrio fibrisolvens A38 and Streptococcus bovis. The morphological changes of these species implicated the cell wall as a target of tannin toxicity (Jones et al., 1994). In turn, both hydrolysable tannins and proanthocyanidines suppressed the oxacillin-resistance of MRSA (Hatano et al., 2005).

The number of publications dealing with antimicrobial activity of yet another group of phenolics, cummarins, is scarce and generally it can be concluded that this property has not been evaluated systematically (Borges et al., 2005; Cechinel Filho et al., 2009).

\section{Silver and gold nanoparticles}

Nanoparticles (NPs) are defined as the clusters of atoms of size ranged from 1 to $100 \mathrm{~nm}$. Their network forms are called nanowires. NPs are characterized by a very large surface area to volume ratio (Rai et al., 2009). Copper, zinc, magnesium but especially silver and gold NPs display antibacterial activity and are used for various healthcare, hygiene and personal care purposes and also in water-treatment (Edwards-Jones, 2009; Gurunathan et al., 2009). The conventional methods of NPs preparation involves the use of highly toxic chemical agents, however more friendly techniques have also been developed (Baker et al., 2005; Wangoo et al., 2008). Recently the biological systems for nanoparticles synthesis were elaborated, the process is known as "green synthesis". Sharma and coworkers (2009) described the production of silver nanoparticles (AgNPs) by plant extract containing proteins able to reduce Ag cations. Bacteria and fungi can also be explored for AgNPs production. Their biosynthesis was achieved through reduction of $\mathrm{Ag}^{+}$ ions by Klebsiella pneumoniae (Shahverdi et al., 2007), E. coli (Gurunathan et al., 2009) and Bacillus licheniformis (Vaidyanathan et al., 2010). Ingle et al. (2008) and Gade et al. (2008) reported the use of fungi, respectively Fusarium accuminatum and Aspergillus niger, for the production of AgNPs. In turn $\mathrm{He}$ et al. (2008) described the synthesis of gold nanowires using an extract of Rhodopseudomonas capsulata. It

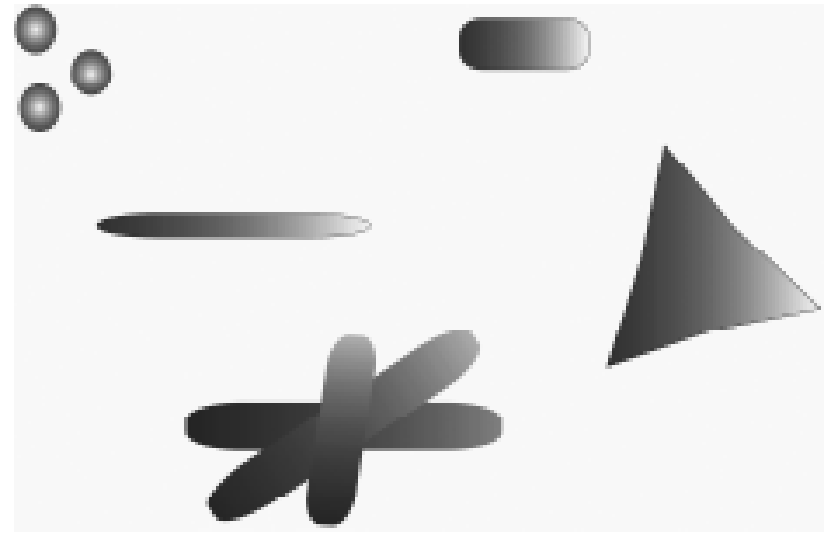

Fig. 3. Different types of silver and gold nanoparticles

should be noted that recently microbial synthesis of selenium, tellurium platinum, thitania, uranitnie and other nanoparticles by bacteria, actinomycetes, fungi, yeasts and viruses was also reported (Narayanan and Sakthivel, 2010).

Silver in ionic form has been known for centuries to cure venereal diseases, bone and perianal abscesses, eye diseases and burns. It was proved that $\mathrm{Ag}^{+}$was active against various bacterial species e.g. E. coli, S. aureus, Klebsiella sp. and Pseudomonas sp. (Rai et al., 2009; Chopra, 2007). AgNPs have an advantage over ionic silver because they show reduced toxicity and 1.4-1.9 times higher antibacterial potential (Ingle et al., 2008). Reports pointing to silver toxicity, including arygria and the deposition of silver in liver are rather scarce (Tomi et al., 2004; Landsdown, 2006).

The antibacterial effect of AgNPs depends on their size. Smaller-sized particles show stronger antibacterial activity due to their higher surface area to volume ratio (Morones et al., 2005). It was also proved that the truncated triangular AgNPs displayed stronger bacteriocidal action against E. coli compared with spherical and rod-shaped nanoparticles, suggesting shape-dependent interaction at least with Gram-negative bacteria (Pal et al., 2007). Different shapes of silver and gold nanoparticles are shown in Figure 3. Several studies demonstrated that bacterial membranes constituted the main target of AgNPs antibacterial activity, nanoparticles caused their disruption probably due to the production of reactive oxygen species (ROS), including free radicals. Production of ROS is one of the primary mechanisms of nanoparticle toxicity; it may result in oxidative stress, inflammation, and consequent damage not only of membranes but also of DNA and proteins (Singh et al. 2008). The model of bacterium - nanoparticle interactions presented by Neal (2008) is based on contact-mediated membrane lipid peroxidation by arising reactive oxygen species. Contact was facilitated by electrostatic forces between nanoparticles and negatively charged cell envelopes. Scanning and transmission electron 
microscopy images confirmed the formation of pits in the E. coli cell wall and the accumulation of silver in bacterial membranes which increases permeability and therefore results in cell death (Sondi and SalopekSondi, 2007). AgNPs may target the bacterial membrane, leading to a dissipation of the proton motive force as shown by proteomic data and biochemical studies. Short exposure of E. coli cells to AgNPs resulted in alterations in the expression of several envelope proteins (OmpA, OmpC, OmpF, OppA, MetQ) and heat shock proteins, (IbpA, IbpB and 30S ribosomal subunit) (Lok et al., 2006).

AgNPs interaction with membrane sulfur-containing proteins was also proven (Rai et al., 2009). Membrane disruption allowed the passage of AgNPs into cytoplasm causing subsequent damage of DNA and other phosphorus containing compounds and impairing the respiratory chain and cell division. The antibacterial activity of AgNPs is enhanced by their decomposition and the release of $\mathrm{Ag}$ ions within bacterial cell (Feng et al., 2000; Morones et al., 2005).

The antibacterial activity of AgNPs was well proven basing on in vitro experiments. Activity against MRSA (Panacek et al., 2006), E. coli (Sondi and Salopek-Sondi, 2007; Morones et al., 2005; Pal et al., 2007; Yoon et al., 2007), P. aeruginosa (Morones et al., 2005), Vibrio cholera (Morones et al., 2005) and B. subtilis (Yoon et al., 2007) was reported. Kim and coworkers (2007) demonstrated that E. coli was inhibited at low concentration of AgNPs whereas the growth-inhibitory effect of $S$. aureus was mild. The efficient antibacterial activity of AgNPs impregnated with bacterial cellulose against $E$. coli and $S$. aureus has also been demonstrated (Castellano et al., 2007). Sucrose and soluble and waxy corn starch can also serve as stabilizers (Valodkar et al., 2010). Synergistic antimicrobial activity of AgNPs with penicillin G, amoxicillin, erythromycin, clindamycin and vancomycin against $S$. aureus and E. coli was observed (Shahverdi et al., 2007). It was also shown that AgNPs prevent the formation of bacterial biofilms, e.g. biofilms formed by P. aeruginosa and S. epidermidis were inhibited in more than 95\% (Kalishwaralal et al., 2010). This property made these nanoparticles especially useful in controlling biofilms within the oral cavity (Allaker, 2010). Biofilm formation was inhibited due to the ability of AgNPs to prevent the initial step in biofilm development i.e. microbial adhesion to various surfaces (Monteiro et al., 2009).

AgNPs are characterized by so many medical and technological applications that they are considered as new antibacterial agents revolutionizing applied medicine. They are used in wounds and ulcers healing, usually in the form of dressings and creams (Cortivo et al., 2010; Jun et al., 2007). They are also utilized to coat medical devices such as catheters, den- tures or surgical masks (Li et al., 2006). Silver, together with copper, is commonly used to inhibit bacterial and fungal growth in chicken farms and in post harvested cleaning of oysters (Singh et al., 2008). AgNPs and other nanoparticles can be used in water filtration and disinfection (Li et al., 2008; Jain and Pradeep, 2005) as well in the production of textiles, both non-toxic and possessing antimicrobial properties (Dastjerdi and Montazer, 2010) and in the production of antimicrobial nanopaints (Kumar et al., 2008).

Gold nanoparticles (AuNPs) also can be used as antimicrobial agents. In this case the majority of papers describes their application as a tool to deliver other antimicrobials or as a factor enhancing photodynamic destruction of bacteria (Pissuwan et al., 2009). AuNPs were very suitable for delivering drugs, including antibiotics; AuNPs conjugates with vancomycin proved to be 50 -fold more active that the free antibiotic against Enterococcus faecium and E. faecalis (Gu, 2003). The AuNPs-ciprofloxacin and aminoglycosidic antibiotics conjugates were also described (Tom et al., 2004; Grace and Pandian, 2007). The role of AuNPs was to facilitate the attachment of conjugated antibiotic to bacterium and therefore penetrating of cell wall. However it should be stressed that there is no consensus concerning the efficacy of AuNPsantibiotic conjugates compared with the same dosage of free antibiotic, e.g. Rosemary et al. (2006) found that AuNPs enhanced the efficacy of ciprofloxacin against $E$. coli what was not observed for gentamycin (Burygin et al., 2009).

AuNPs were also used as stabilizers for various antimicrobial photosensitizers. Four-fold increase of $S$. aureus elimination was observed when toluidine blue O-AuNPs conjugates and methylene blue-AuNPs conjugates were used in photodynamic therapy compared to dyes alone (Gil-Tomás et al., 2007; Perni et al., 2009). AuNPs enhanced the absorption of light due to their plasmon resonance (Pitsillides et al., 2003) which could cause local hyperthermic effect leading to the efficient destruction of E. coli irradiated with X-rays (Simon-Deckers et al., 2009), P. aeruginosa exposed to near-infrared laser (Norman et al., 2008) or $S$. aureus irradiated with strong laser light (Zharov et al., 2006).

AuNPs are very useful for detection and diagnosis of bacteria even in complex media like blood (Kaittanis et al., 2010), this being mainly based on the detection of bacterial DNA by change of color (Elghanian et al., 1997). They have been used for fast, accurate and sensitive detection of Staphylococcus sp. (Storhoff et al., 2004) and M. tuberculosis (Baptista et al., 2006; Veigas et al., 2010). AuNPs were also applied to improve the sensitivity of bacterial detection methods based on flow cytometry and fluorescence (Zaharov et al., 2007; Wang et al., 2009). 


\section{Natural and synthetic dyes and photodynamic therapy}

The antimicrobial effect of natural and synthetic dyes has been known for many decades. Already in the beginning of the last century proflavine, acriflavine, crystal violet and brilliant green were used against bacterial infections, mainly to cure infected wounds (Wainwright, 2008; Wainwright, 2010). Preoperative use of iodine still remains a common practice. Gentian (crystal) violet was shown to be very efficient in the eradication of MRSA from skin lesions (Saji et al., 1995). Recently it was shown that the tiazol dye, thioflavin $\mathrm{T}$, exerted a strong inhibitory effect on $S$. aureus, the effect on E. coli was less pronounced (Lakatoš, 2010). The list of dyes with antibacterial properties included also pigments synthesized by microorganisms (Wolska et al., 2010b). The pigment produced by $P$. aeruginosa - pyocyanin, due to its unique redox properties, actively eliminated many bacterial species, especially Gram-positive aerobes (Baron and Rove, 1981). In turn violacein extracted from Chromobacterium violaceum displayed a potent antileishamanial activity (Leon et al., 2001).

Many dyes can serve as photosensitizers, sometimes called photomicrobial agents, and are applied in photodynamic antimicrobial therapy (PACT). Photosensitizers can be activated by visible light to generate cytotoxic radicals, superoxide radicals and singlet oxygen $1 / 2 \mathrm{O}_{2}$ which are the reactive oxygen species (ROS). ROS are highly toxic to various type of cells, including bacteria, causing the damage of the outer membrane, cell wall, ribosomes and nucleic acids and thus impairing many cellular functions (for review see Wainwright, 2010; Ryskova et al., 2010). Photosensitizers are usually dyes such as methylene blue (Gad et al., 2004), porphyrins (Hamblin et al., 2005), crystal violet (Saji et al., 1995), iodocyanine green (Unno et al., 2008) and erytrosine (Wood et al., 2006).The latter is of special interest because it can be used for the therapy of oral plaque biofilms (Wood et al., 2006). Positively charged (cationic) photosensitizers such as methylene blue and crystal violet act as broad-spectrum antimicrobials, while the negatively charged (anionic) compounds lack efficacy against Gram-negative species (Demidova et al., 2005). This is because anionic photosensitizers are not able to penetrate the lipopolysaccharide outer membrane of Gram-negative bacteria. In practice photosensitizers are usually activated by red light and the preferable source of light is low-power lasers (Ryskova et al., 2010). The stabilization of various photosensitizers by AuNPs was described in the previous chapter. Beside dyes, also fullerenes which are stable chemical molecules composed of 60 carbon atoms arranged in a soccer ball- shaped structure are proved to be the efficient photosensitizers (Krokosz, 2007).

Photodynamic therapy is used mainly in the treatment of local infections. Its efficacy was proved in healing cutaneous infections e.g. poor-healing wounds caused by Mycobacterium marinum (Rallis and Koumantaki-Mathioudaki, 2007) and oral microbial related diseases such as periodontitis (Liu et al., 2009). It was clinically studied for leishmaniasis (Dai et al., 2009). It should be stressed that photodynamic therapy can be applied in the eradication of antibioticresistant pathogens e.g. MRSA (Griffiths et al., 1997), VRE (Soncin et al., 2002) and P. aeruginosa (Minnock et al., 1996) which are life-threat danger in hospitals. Recently it was shown that two water soluble photosensitizers: methylene blue and neutral red enclosed in liposomes gave a stronger antibacterial effect than their free forms (Nisnevitch et al., 2010). It should be also noted that photodynamic therapy was applied and found to be efficient in treating lung, stomach and skin tumors (Maisch et al., 2005).

\section{Conclusions}

The huge and constantly growing amount of papers describing new antibacterial therapeutics reflects an urgent need to find efficient antimicrobials which can be an alternative to antibiotics. Plants and their extracts have been used even in ancient times for medical purposes. Recently, studies are focused on the activity of purified compounds. Trials aimed at resolving the mechanism of their action are also performed. The majority of studies are held in vitro but the results of preclinical and clinical trial have also been reported. As it was shown that many plant compounds exert a cytotoxic effect (Zhang et al., 2007) efforts have been made to synthesize derivatives with less toxicity and better water solubility (e.g. Farina et al., 1998; Liu, 2005), which can enhance the possibility of their therapeutic application. Studies on the antibacterial activity of silver and gold nanoparticles are more advanced and also comprise their synergism with commonly used antibiotics and the application of AuNPs in stabilizing photosensitizers used in photodynamic therapy, which is a very proficient new antibacterial strategy.

Considering the enormous scientific effort put in elaborating new antibacterial compounds and strategies, alternative possibilities to cope with bacterial diseases can emerge in the near future.

\section{Acknowledgment}

This study was partially supported by Ministry of Science and Higher Education grant NN302 027937. 


\section{Literature}

Ahmed A.A., A.A. Mahmoud, H.J. Williams, A.I. Scott, J.H. Reinbenspiesand and T.J. Mabry. 1993. New sesquiterpene $\alpha$-methylene lactones from the Egyptian plant Jasonia candicans. J. Nat. Prod. 56: 1276-1280.

Allaker R.P. 2010. The use of nanoparticles to control oral biofilm formation. J. Dent. Res. 89: 1175-1186.

Amaral J.A., A. Ekins S.R. Richards and R. Knowles. 1998. Effect of selected monoterpenes on methane oxidation, denitrification, and aerobic metabolism by bacteria in pure culture. Appl. Environ. Microbiol. 64: 520-525.

Baker C., A. Pradhan, L. Pakstis, D.J. Pochan and S.I. Shah. 2005. Synthesis and antibacterial properties of silver nanoparticles. J. Nanosci. Nanotechnol. 5: 244-249.

Baptista P.V., M. Koziol-Montewka, J. Paluch-Oles, G. Doria and R. Franco. 2006. Gold-nanoparticle-probe-based assay for rapid and direct detection of Mycobacterium tuberculosis DNA in clinical samples. Clin. Chem. 52: 1433-1434.

Baron S. and J.J. Rove. 1981. Antibiotic action of pyocyanin Antimicrob. Agents Chemother. 20: 814-830.

Borges F., F. Roleira, N. Mihazes, L. Santana and E. Uriarte. 2005. Simple coumarins and analogues in medical chemistry: occurrence, synthesis and biological activity. Curr. Med. Chem. 12: 887-916.

Borris R.P. 1996. Natural products research: perspectives from a major pharmaceutical company. J. Ethnopharmacol. 51: 29-38. Brantner A., Ž. Maleš, S. Pepelnjak and A. Antolić. 1996. Antimicrobial activity of Paliurus spina-christi Mill. (Christ's thorn). J. Ethnopharmacol. 52: 119-122.

Burygin G.L., B.N. Khlebtstov, A.N. Shantrokha, L.A. Dykman, V.A. Bogatyrev and N.G. Khlebtsov. 2009. On the enhanced antibacterial activity of antibiotics mixed with gold nanoparticles. Nanoscale Res. Lett. 4: 794-801.

Cabrera C., R. Artacho and R. Giménez. 2006. Beneficial effect of green tea - a review. J. Am. Coll. Nutr. 25: 79-99.

Castellano J.J., S.M. Shafii, F. Ko, G. Donate, T.E. Wright, R.J. Mannari, W.G. Payne, D.J. Smith, M.C. Robson. 2007. Comparative evaluation of silver-containing antimicrobial dressings and drugs. Int. Wound J. 4: 114-122.

Cazarolli L.H., L. Zanatta, E.H. Alberton, M.S. Figueiredo, P. Folador, R.G. Damazio, M.G. Pizzolatti and F.R. Silva. 2008. Flavonoids: prospective drug candidates. Mini Rev. Med. Chem. 8: 1429-1440.

Cechinel Filho V., C. Meyre-Silva and R. Neiro. 2009. Chemical and pharmacological aspects of the genus Calophyllum. Chem. Biodivers. 6: 313-327.

Chen J.-C., T.-H. Ho, Y.-S. Chang, S.-L. Wu, C.-C. Li and C.-Y. Hsiang. 2009. Identification of Escherichia coli enterotoxin inhibitors from traditional medical herbs in silico, in vitro and in vivo analyses. J. Ethnopharmacol. 121: 372-378.

Chibani-Chennoufi S., J. Sidoti, A. Bruttin, E. Kutter, S. Sarker and H. Brussow. 2004. In vitro and in vivo bacteriolytic activities of Escherichia coli phages: implications for phage therapy. Antimicrob. Agents Chemother. 48: 2558-2569.

Chopra I. 2007. The increasing use of silver-based products as antimicrobial agents: a useful development or a case for concern? J. Antimicrobial. Chem. 59: 587-590.

Chung K.T., T.Y. Wong, C.I. Wei, Y.W. Huang and Y. Lin. 1998. Tannins and human health: a review. Crit. Rev. Food Sci. Nutr. 38: 421-464.

Cimolai N. and T. Cimolai. 2007. The cranberry and urinary tract. Eur. J. Clin. Microbiol. Infect. Dis. 26: 767-776.

Comini L.R., S.C. Núňez Montoya, P.L. Páez, G.A. Argüello, I. Albesa and J.L. Cabrera. 2010. Antibacterial activity of anthra- quinone derivatives from Heterophyllaea postulate (Rubiaceae) J. Photochem. Photobiol. B.

Copp B.R. and A.N. Pearce. 2007. Natural product growth inhibitors of Mycobacterium tuberculosis. Nat. Prod. Rep. 24: 278-297. Cortivo R., V. Vindigni, L. Iacobellis, G. Abatangelo, P. Pinton and B. Zavan. 2010. Nanoscale particle therapies for wounds and ulcers. Nanomedicine 5: 641-656.

Cowan M.M. 1999. Plant product as antimicrobial agents. Clin. Microbiol. Rev. 12: 564-582.

Dai T., Y.-Y. Huang and M.R. Hamblin. 2009. Photodynamic therapy for localized infections - state of art. Photodiag. Photodyn. Ther. 6: 170-188.

Dastjerdi R. and M. Montazer. 2010. A review on the application of inorganic nano-structured materials in the modification of textiles: focus on anti-microbial properties. Colloids Surf. B. Interfaces. 79: 5-18

de la Iglesia R., F.I. Milagro, J. Campión, N. Boqué and J.A. Martinez. 2010. Healthy properties of proanthocyanidins. Biofactors 36: 159-168.

Demidova T.N. and M.R. Hamblin. 2005. Effect of cell-photosensitizer binding and cell density on microbial photoinactivation Antimicrob. Agents Chemother. 49: 2329-2335.

Donadio S., S. Maffiolo, P. Monciardini, M. Sosio and D. Jabes. 2010. Antibiotic discovery in the twenty-first century: current trends and future perspectives. J. Antibiot. (Tokyo) 63 : 423-430.

Dryden G.W., M. Song and C. McClain. 2006. Polyphenols and gastrointestinal diseases. Curr. Opin. Gastroenterol. 22: 165-170. Edwards-Jones V. 2009. The benefits of silver in hygiene, personal care and healthcare. Lett Appl. Microbiol. 49: 147-152.

EIghanian R., J.J. Storhoff, R.C. Mucic, R.L. Letsinger and C.A. Mirkin. 1997. Selective colorimetric detection of polynucleotides based on the distance-dependent optical properties of gold nanoparticles. Science 277: 1078-1081.

Farina C., M. Pinza and G. Pifferi. 1998. Synthesis and antiulcer activity of new derivatives of glycyrrhetic, oleanolic and ursolic acids. Pharmacology 53: 22-32.

Feng Q.J., J. Wu, G.Q. Chen, F.Z. Cui, T.N. Kim and J.Q. Kim. 2000. A mechanistic study of the antibacterial effect of silver ions on Escherichia coli and Staphyloccocus aureus. J. Biomed. Matter 52: 662-668.

Fontanay S., M. Grare, J. Mayer, C. Finance and R.E. Duval. 2008. Ursolic, oleanolic and betulic acids: Antibacterial spectra and selectivity indexes. J Ethnopharmacol. 120: 272-276.

Friedman M. 2007. Overwiew of antibacterial, antitoxin, antiviral and antifungal activities of tea flavonoids and teas. Mol. Nutr. Food Res. 51: 116-134.

Gad F., T. Zahra, T. Hasan and M.R. Hamblin. 2004. Effect of growth phase and extracellular slime on photodynamic inactivation of Gram-positive pathogenic bacteria. Antimicrob. Agents Chemother. 48: 2173-2178.

Gade A.K., P. Bonde, A.P. Ingle, P.D. Marcato, N. Duran and M.K. Rai. 2008. Explotation of Aspergillus niger for synthesis of silver nanoparticles. J. Biol. Mater. Bioener. 2: 1-5.

Ge F., F. Zeng, S. Liu, N. Guo, H. Ye, Y. Song, J. Fan, X. Wu, X. Wang, X. Deng, Q. Jin and L. Yu. 2010. In vitro synergistic interactions of oleanolic acid in combination with isoniazid, rifampicin or ethambutol against Mycobacterium tuberculosis. J. Med. Microbiol. 59: 567-72.

Gil-Thomás J., S. Tubby, I.P. Parkin, N. Narband, L. Dekker, S.P. Nair, M. Wilson and C. Street. 2007. Lethal photosensitisation of Staphylococcus aureus using toluidine blue O-tioproningold nanoparticle conjugate. J. Mat. Chem. 17: 3739-3746.

Górski A., A. Międzybrodzki, J. Borysowski, B. WeberDąbrowska, M. Łobocka, W. Fortuna, S. Letkiewicz, M. Zimecki 
and G. Filby. 2009. Bacteriophage therapy for the treatment of infections. Curr. Opin. Investig. Drugs 10: 766-774.

Grace N.A. and K. Pandian. 2007. Antibacterial efficacy of aminoglycosidic antibiotics protected gold nanoparticles - A brief study. Colloids Surf. A Physicochem. Eng. Asp. 297: 63-70.

Griffiths M.A., B.W. Wren and M. Wilson. 1997. Killing of methicillin-resistant Staphylococcus aureus in vitro using aluminium disulphonated phthalocyanine, a light-activated antimicrobial agent. J. Antimicrob. Chemother. 40: 873-876.

Gu H., P.L. Ho, E. Tong, L. Wang, B. Xu. 2003. Presentation of vancomycin on nanoparticles to enhance antimicrobial activities. Nano Lett. 3: 1261-1263.

Gurunathan S., K. Kaliswaralal, R. Vaidyanathan, D. Venkataraman, S.R. Pandian, J. Hariharan and S.H. Eom. 2009. Biosynthesis, purification and characterization of silver nanoparticles using Escherichia coli. Colloids Surf. B. Interfaces 74: 328-335.

Habtermariam S., A.I. Gray and P.G. Waterman. 1993. A new antibacterial sesquiterpene from Premna oligotricha. J. Nat. Prod. 56: $140-143$

Hamblin M.R., J. Viveiros, C.H. Yang, A. Ahmadi, R.A. Ganz and M.J. Tolkoff. 2005. Helicobacter pylori accumulates photoactive porphyrins and is killed by visible light. Antimicrob. Agents Chemother. 49: 2822-2827.

Harada H. and N. Misawa. 2009. Novel approaches and achievements in biosynthesis of functional isoprenoids in Escherichia coli. Appl. Microbiol. Biotechnol. 84: 1021-1031.

Hatano T., M. Kusuda, K. Inada, T.O. Ogawa, S. Shiota, T. Tsuchiya and T. Yoshida. 2005. Effects of tannins and related polyphenols on methicillin-resistant Staphylococcus aureus. Phytochemistry 66: 2047-2055.

He S., Y. Zhang, Z. Guo and N. Gu. 2008 . Biological synthesis of gold nanowires using extact of Rhodopseudomonas capsulata. Biotech. Prog. 24: 476-480.

Hillard E.A., F.C. de Abreu, D.C. Ferreira, G. Jaouen, M.O. Goulart, C. Amatore. 2008. Electrochemical parameters and techniques in drug development, with an emphasis on quinones and related compounds. Chem Commun. (Camb.) 21: 2612-2628.

Högberg L. D., A. Heddini and O. Cars. 2010. The global need for effective antibiotics: challenges and recent advances. Trends Pharmacol. Sci. 31: 509-515.

Ingle A., A. Gade, S. Pierrat, C. Sonnichsen and M. Rai. 2008 Mycosynthesis of silver nanoparticles using the fungus Fusarium acuminatum and its activity against some human pathogenic bacteria. Curr. Nantechnol. 4: 141-144.

Jain P. and T. Pradeep. 2005. Potential of silver nanoparticlecoated polyurethane foam as an antibacterial water filter. Biotechnol. Bioeng. 90: 59-63.

Jones G.A., T.A. McAllister, A.D. Muir and K.J. Cheng. 1994. Effects of sainfoin (Onobrychis viciifolia Scop.) condensed tannins on growth and proteolysis by four strains of ruminal bacteria. Appl. Environ. Microbiol. 60: 1374-1378.

Jun J., D. Yuan-Yuan, W. Shao-feng, W. Zhong-yi. 2007. Preparation and characterization of antibacterial silver-containing nanofibers for wound dressing applications. J. US-China Med. Sci. 4: 52-54.

Kaittanis C., S. Santra and J.M. Perez. 2010. Emerging nanotechnology based strategies for the identification of microbial pathogenesis. Adv. Drug Deliv. Rev. 62: 408-423.

Kalishwaralal K., S. BarathManiKanth, S.R. Pandian, V. Deepak and S. Gurunathan. 2010. Silver nanoparticles impede the biofilm formation by Pseudomonas aeruginosa and Staphylococcus epidermidis. Colloids Sur. B Biointerfaces 79: 340-344.

Kazumi M.H., A. Malik, S. Hammed, N. Akhtar and S. Noor Ali. 1994. An anthraquinone derivative from Cassia italica. Phytochemistry 36: 761-763.
Kim J.S., E. Kuk, K.N. Yu, J.H. Kim, S.J. Park, H.J. Lee, S.H. Kim,. Y.K. Park, C.Y. Hwang, Y.K. Kim, Y.S. Lee, D.H. Jeong and M.H. Cho. 2007. Antimicrobial effect of silver nanoparticles. Nanomedicine 3: 95-101.

Koleckar V., K. Kubikova, Z. Rehakova, K. Kuca, D. Jun, L. Jahodar and L. Opletal. 2008. Condensed and hydrolysable tannins as antioxidants influencing the health. Mini Rev. Med. Chem. 8: 436-447.

Koo M.W. and C.H. Cho. 2004. Pharmacological effect of green tea on the gastrointestinal system. Eur. J. Pharmacol. 500: 177-185. Koru O., F. Toksoy, C.H. Acikel, Y.M. Tunca, M. Baysallar, A. Uskudar Guculu, E. Akca, A. Ozkok Tuylu, K. Sorkun, M. Tanyuksel and B. Salih. 2007. In vitro antimicrobial activity of propolis samples from different geographical origins against certain oral pathogens. Anaerobe 13: 140-145.

Koyama J. 2006. Anti-infective quinone derivatives of recent patents. Recent Pat. Antiinfect. Drug Discov. 1: 113-125.

Kozai K., J. Suzuki, M. Okada and N. Nagasaka. 1999. Effect of oleanolic acid-cyclodextrin inclusion compounds on dental carries by in vitro experiment in rat-carries model. Microbios 97: 179-188. Krokosz A. 2007. Fullerenes in biology (in Polish). Post. Biochem. 53: 91-96.

Kubo I., H. Muroi and M. Himejima. 1992. Antibacterial activity of totarol and its potentiation. J. Nat. Prod. 55: 1436-1440.

Kumar A., P. K. Vemula, P. M. Ajayan and G. John. 2008 Silver nanoparticle-embeded antimicrobial paints based on vegetable oil. Nat. Mater. 7: 236-241.

Kurek A., A.M. Grudniak, M. Szwed, A. Klicka, L. Samluk and K.I. Wolska. 2010. Oleanolic acid and ursolic acid affect peptidoglycan metabolism in Listeria monocytogenes. Anton, Leuven. 97: 1143-1146.

Kuźma L., M. Różalski, E. Walencka, B. Różalska and H. Wysokińska. 2007. Antimicrobial activity of diterpenoids from hairy roots of Salvia sclarea L.: salvipisone as a potential anti-biofilm agent active against antibiotic resistant Staphylococci. Phytomedicine 14: 31-35.

Lakatoš B., B. Kaliňková, D. Hudecová. and L. Varečka. 2010 New effect and applications of thioflavins. Centr. Eur. J. Biol. 5: 143-150.

Landsdown A.B. 2006. Silver in health care: antibacterial effect and safety in use. Curr. Probl. Dermatol. 33: 17-34.

Leon L.L., C.C. Miranda, A.O. De Souza and N. Durán. 2001. Antleishmanial activity of the violacein extracted from Chromobacterium violaceum. J. Antimicrob. Chemother. 48: 449-450.

Levy S.B. 1998. The challenge of antibiotics resistance. Sci. Am. 278: 46-53.

Li Y., P. Leung, Q.W. Song and E. Newton. 2006. Antimicrobial effect of surgical masks coated with nanoparticles. J. Hosp. Infect. 62: 58-63.

Li Q., S. Mahendra, D.Y. Lyon, L. Brunet, M.V. Liga, D. Li and P.J. Alvarez. 2008. Antimicrobial nanomaterials for water disinfection and microbial control: potential applications and implications. Water Res. 42: 4591-4602.

Li H.Q., L. Shi, Q. S. Li, P.G. Liu, Y. Luo, J. Zhao and H.L. Zhu. 2009. Synthesis of C(7) modified chrysin derivatives designing to inhibit beta-ketoacyl-acyl carrier protein synthetase III (FabH) as antibiotics. Bioorg. Med. Chem. 17: 6264-6269.

Liu P.F., W.H. Zhu and C.M. Huang. 2009. Vaccines and photodynamic therapies for oral microbial-related diseases. Curr. Drug. Metab. 10: 90-94.

Liu J. 2005. Oleanolic and ursolic acids: Research perspectives. J. Ethnopharmacol. 100: 92-94.

Lok Ch-M., Ch-M. Ho, R. Chen, Q-Y. He, W-Y. Yu, H. Sun, Kwong-Hang, P. Tam, J-F. Chiu and Ch-M. Chi-Ming Che. 2006. Proteomic analysis of the mode of antimicrobial action of silver nanoparticles. J. Prot. Res. 5: 916-924. 
Maisch T., C. Bosi, R.M. Szeimies, N. Lehn and C. Abels. 2005. Photodynamic effect of novel XF porfyrin derivatives on prokaryotic and eukaryotic cells. Antimicrob. Agents Chemother. 49: $1542-1552$.

Males Z., A.H. Branter, K. Sović, K.H. Pilepić and M. Plazibat. 2006. Comparative phytochemical and antimicrobial investigations of Hypericium perforatum L. subsp. perforatum and H. perforatum subsp. angustifolium (DC.) Gaudin. Acta Pharm. 56: 359-367.

Mason T.L. and B.P. Wasserman. 1987. Inactivation of red beet beta-glucan synthetase by native and oxidized phenolic compounds. Phytochemistry 26: 2197-2202.

Minnock A., D.I. Vernon, J. Schofield., J. Griffith., J. Howard Parish and S.B. Brown. 1996. Photoinactivation of bacteria. Use of cationic water-soluble zinc phthalocyanine to photoinactivate both Gram-negative and Gram-positive bacteria. J. Photochem. Photobiol. B. Biol. 32: 159-64.

Monteiro D.R., L.P. Gorup, A.S. Takamiya, A.C. RuvolloFilho, E.R. de Camargo and D. Barros Barbosa. 2009. The growing importance of materials that prevent microbial adhesion: antimicrobial effect of medical devices containing silver. Int. J. Antimicrob. Agents 34: 103-110.

Morones J.R., J.L. Elechigerra, A. Camacho and J.T. Ramirez. 2005. The bacterial effect of silver nanoparticles. Nanotechnology 16: 2346-2353.

Mourer M., H.M. Dibama, S. Fontanay, M. Grare, R.E. Duval, C. Finance and J.B. Regnouf-de-Vains. 2009. p-Guanidinoethyl calixarene and parent phenol derivatives exhibiting antibacterial activities. Synthesis and biological evaluation. Bioorg. Med. Chem. 17: 5496-5509.

Myles D.C. 2003. Novel biologically active natural and unnatural products. Curr. Opin. Biotechnol. 14: 627-633.

Nakayama T., T. Hashimoto, K. Kajiyaand S. Kumazawa. 2000. Affinity of polyphenols for lipid bilayers. Biofactors 13: 147-151.

Nakahara K., S. Kawabata, H. Ono, K. Ogura, T. Tanaka, T. Ooshima and S. Hamada. 1993. Inhibitory effect of oolong tea polyphenols on glucosyltransfrases of mutant streptococci. Appl. Environ. Microbiol. 59: 968-973.

Narayanan K.B. and N. Sakthivel. 2010. Biological synthesis of metal nanoparticles by microbes. Adv. Colloid Sci. 156: 1-13. Neal A.I. 2008. What can be inferred from bacterium - nanoparticle interactions about the potential consequences of environmental exposure to nanoparticles? Exotoxicobiology 7: 362-371.

Nisnevitch M., F. Nakonechny and Y. Nitzan. 2010. Photodynamic antimicrobial chemotherapy by liposome-encapsulated water-soluble photosensitizers. Bioorg. Chim. 36: 396-402.

Norman R.S., J.W. Stowe, A. Gole, C.J. Murphy and T.L. SaboAltwood. 2008. Targeted photothermal lysis of pathogenic bacteria, Pseudomonas aeruginosa, with gold nanorods. Nano. Lett. 8: 302-306.

Okuda T. 2005. Systematics and health effects of chemically distinct tannins in medical plants. Phytochemistry 66: 2012-2031.

Pal S., Y.K. Tak and J.M. Song. 2007. Does the antibacterial activity of silver nanoparticles depend on the shape of the nanoparticle? A study of the Gram-negative bacterium Escherichia coli. Appl. Environ. Microbiol. 27: 1712-1720.

Panacek A., L. Kvitek, R. Prucek, M. Kolar, R. Vecerova and N. Pizurova. 2006. Silver colloid nanoparticles: synthesis, characterization and their antibacterial activity. J. Phys. Chem. 110: 16248-16243.

Perni S., C. Piccirillo, J. Pratten, P. Prokopovich, W. Chrzanowski, P. Parkin and M. Wilson. 2009. The antimicrobial properties of light-activated polymers containing methylene blue and gold nanoparticles. Biomaterials 30: 89-93.
Pissuwan D., C.H. Cortie, S.M. Valenzuela and M.B. Cortie. 2009. Functionalised gold nanoparticles for controlling pathogenic bacteria. Trends Biotechnol. 28: 207-213.

Pitsillides C.M., E.K. Joe, X Wei, R.R. Anderson and C.P. Lin. 2003. Selective cell targeting with light-absorbing microparticles with nanoparticles. Biophys. J. 84: 4023-4032.

Pommier Y., E. Leo, H. Zhang and C. Marchand. 2010. DNA topoisomerases and their poisoning by anticancer and antibacterial drugs. Chem. Biol. 28: 421-433.

Rai M., A. Yadav and A Gade. 2009. Silver nanoparticles as a new generation of antimicrobials. Biotech. Adv. 27: 76-83.

Rallis E. and E. Koumantaki-Mathioudaki. 2007. Treatment of Mycobacterium marinum cutaneous infections. Expert Opin. Pharmacother. 8: 2965-2978.

Ren D., R. Zuo, A.F. Gonzalez Barrios, L.A. Bedzyk, G.R. Eldridge, M.E. Pasmore and T.K. Wood. 2005. Differential gene expression for investigation of Escherichia coli biofilm inhibition by plant extract ursolic acid. Appl. Environ. Microbiol. 71: 4022-4034

Rios J.L. and M.C. Recio. 2005. Medical plants and antimicrobial activity. J. Ethnopharmacol. 100: 80-84.

Rosemary M.J., I. MacLaren and T. Pradeep. 2006. Investigations of the antibacterial properties of ciprofloxacin $\mathrm{SiO}_{2}$. Langmuir 22: $10125-10129$.

Ryskova L., V. Buchta and R. Slezak. 2010. Photodynamic antimicrobial therapy. Centr. Eur. J. Biol. 5: 400-406.

Sacchettini J.C. and C.D. Poulter. 1997. Creating isoprenoid diversity. Science 277: 1788-1789.

Saddiqe Z., I. Naeem and A. Maimoona. 2010. A review of the antibacterial activity of Hypericum perforatum L. J. Ethnopharmacol. 131: 511-521.

Saji M., S. Taguchi, K. Uchiyama, E. Osomo, N. Hayama and H. Ohkumi. 1995. Efficacy of gentian-violet in the eradication of methicillin-resistant Staphylococcus aureus from skin lesions. J. Hosp. Infect. 31: 225-228.

Sakanaka S., N. Shimura, M. Aizawa, M. Kim and T. Yamamoto. 1992. Preventive effect of green tea polyphenols against dental caries in conventional rats. Biosci. Biotechnol. Biochem. 56: 592-594. Savluchinske-Feio S., M.J. Curto, B. Gigante and J.C. Roseiro. 2006. Antimicrobial activity of resin acid derivatives. Appl. Microbiol. Biotech. 72: 430-436.

Shahverdi A.R., A. Fakhimi, H.R. Shahverdi and S.M. Minaian. 2007. Synthesis and effect of silver nanoparticles on the antibacterial activity of different antibiotics against Staphylococcus aureus and Escherichia coli. Nanomedicine 3: 168-171.

Shang X., X. He, M. Li, R. Zhang, P. Fan, Q. Zhang and Z. Jia. 2010. The genus Scutellaria an ethnopharmacological and phytochemical review. J. Ethnopharmacol. 128: 279-313.

Sharma V.K., R.A. Yngard and Y. Lin. 2009. Silver nanoparticles: green synthesis and their antimicrobial activities. $A d v$. Colloid Interface Sci. 145: 83-96.

Simon-Deckers A., S. Loo, M. Mayne-L'hermite, N. HerlinBoime, N. Menguy, C. Reynaud, B. Gouget and M. Carriere. 2009. Size-, composition-, and shape-dependent toxicological impact of metal oxide nanoparticles and carbon nanotubes towards bacteria. Environ. Sci. Technol. 43: 8423-8429.

Singh M., S. Singh, S. Prasada and I.S. Gambhir. 2008. Nanotechnology in medicine and antibacterial effect of silver nanoparticles. Digest J. Nanomat. Biostruct. 3: 115-122.

Smith E., E. Williamson, M. Zloh and S. Gibbons. 2005. Isopimaric acid from Pinus nigra shows activity against multidrugresistant and EMRSA strains of Staphylococcus aureus. Phytother. Res. 19: 538-542.

Soncin M., C. Fabris, A. Busetti, D. Dei, D. Nistri and G. Roncucci. 2002. Approaches to selectivity in the Zn (II)phthalocyanide-photosensitized inactivation of wild-type and 
antibiotic-resistant Staphylococcus aureus. Photochem. Photobiol. Sci. 1: 815-819.

Sondi J. and B. Salopek-Sondi. 2004. Silver nanoparticles as antimicrobial agent: a case study on E. coli as a model for Gramnegative bacteria. J. Colloid Interface 275: 177-182.

Storhoff J.J., A.D. Lucas, V. Garimella, Y.P. Bao and U.R. Müller. 2004. Homogenous detection of unamplified genomic DNA sequences based on colorimetric scatter of gold nanoparticles probes. Nat. Biotechnol. 22: 883-887.

Suresh Babu K., T. Hari Babu, P.V. Srinvas, K. Hara Kishore, U.S. Murthy and J.M. Rao. 2006. Synthesis and biological evaluation of novel C(7) modified chrysin analogues as antibacterial agents. Bioorg. Med. Chem. Lett. 16: 221-224.

Tom R.T., V. Suryanarayanan, P.G. Reddy, S. Baskaran and T. Pradeep. 2004. Ciprofloxacin-protected gold nanoprticles. Langmuir 20: 1909-1914.

Tomi N.S., B. Kranke and W. Aberer. 2004. A silver man. Lancet 363: 532

Tsuchiya H., M. Sato, M. Miyazaki, S. Fuijwara, S. Tanigaki, M. Ohyama, T. Tanaka, and M. Iinuma. 1996 Comparative study on the antibacterial activity of photochemical flavanones against meticillin-resistant Staphylococcus aureus. J. Ethnopharmacol. 50: 27-34.

Unno N., M. Suzuki, N. Yamamoto, K. Inuzuka, D. Sagara and M. Nishiyama. 2008. Indocyanine green fluorescence angiography for intraoperative assessment of blond flow: a feasibility study. Eur. J. Vasc. Endovasc. Surg. 35: 205-207.

Urs N.V.R.R. and J.M. Dunleavy. 1975. Enhancement of the bactericidal activity of peroxidase system by phenolic compounds (Xanthomonas phaseoli var. sojensis, soybeans). Phytopathology 65: 686-690.

Uzel A., K. Sorkun, O. Onçag, D. Cogülu, O. Gençay and B. Salih. 2005. Chemical composition and antimicrobial activities of four different Anatolian propolis samples. Microbiol. Res. 160: 189-195.

Vaidyanathan R., S. Gopalram, K. Kalishwaralal, V. Deepak, S.R. Pandian and S. Gurunathan. 2010. Enhanced silver nanoparticle synthesis by optimization of nitrate reductase activity. Colooids Sur. B Biointerfaces 75: 335-341.

Valodkar M., A. Bhadoria, J. Pohnerkar, M. Mohan and S. Thakore. 2010. Morphology and antibacterial activity of carbohydrate-stabilized silver nanoparticles. Carbohydr. Res. 345: 1767-1773.

Veigas B., D. Machado, J. Perdigao, I. Portugal, I. Couto, M. Viveiros and P.V. Baptista. 2010. Au-nanoprobes for detection of SNPs associated with antibiotic resistance in Mycobacterium tuberculosis. Nanotechnology 21: 415101.
Vijaya K., S. Ananthan and R. Nalini. 1995. Antibacterial effect of teaflavin, polyphenon 60 (Camellia sinensis) and Euphorbia hirta on Shigella spp. - a cell culture study. J. Ethnopharmacol. 49: 115-118.

Wainwright M. 2008. Dyes in the development of drugs and pharmaceuticals. Dyes Pigments 76: 582-589.

Wainwright M. 2010. "Safe" photoantimicrobials for skin and soft-tissue infections. Int. J. Antimicrob. Agents 36: 14-18.

Walencka E., S. Różalska, S. Wysokińska, M. Różalski, L. Kuźma and B. Różalska. 2007. Salvipisone and aethiopinone from Salvia sclarea hairy roots modulate staphylococcal antibiotics resistance and express anti-biofilm activity. Planta Med. 73: $545-551$.

Wang X., L.H. Liu, O. Ramström and M. Yan. 2009. Engineering nanomaterial surfaces for biomedical applications. Exp. Biol. Med. 234: 1128-1139.

Wangoo N., K.K. Bhasin, R. Boro and C.R. Suri. 2008. Facile synthesis and functionalization of water-soluble gold nanoparticles for bioprobe. Anal. Chim. Acta 610: 142-148.

Wansi J.D., D.D. Chiozem, A.T. Tcho, F.A. Toze, K.P. Devkota, B.L. Ndjakou, J. Wandji and N. Sewland. 2010. Antimicrobial and antioxidant effects of phenolic constituents from Klainedoxa gaboniensis. Pharm. Biol. 48: 1124-1129.

Wolska K.I., A.M. Grudniak, B. Fiecek, A. KraczkiewiczDowjat and A. Kurek. 2010 a. Antibacterial activity of oleanolic and ursolic acids and their derivatives. Centr. Eur. J. Biol. 5: 543-553.

Wolska K.I., A.M. Grudniak, A. Kraczkiewicz-Dowjat and A. Kurek. 2010 b. Various functions of selected bacterial pigments (in Polish). Post. Mikrobiol. 40: 105-114.

Wood S., D. Metcalf, D. Devine and R. Robinson. 2006. Erythrosine is a potential photosensitizer for the photodynamic therapy of oral plaque biofilms. J. Antimicrob. Chemother. 57: 680-684. Wright G.D. 2010. Antibiotic resistance in the environment: a link to the clinic? Curr. Opin. Microbiol. 13: 589-594.

Yoon K-Y, J.H. Byeon, J.-H. Park and J. Hwang. 2007. Susceptibility constants of Escherichia coli and Bacillus subtilis to silver and copper nanoparticles. Sci. Tot. Environm. 373: 572-575. Zharov V.P., E.I. Galanzha and W. Tuchin. 2007. Photothermal flow cytometry in vitro for detection and imaging of individual moving cells. Cytometry A 71: 191-206.

Zharov V.P., K.E. Mercer, E.N. Galitovskaya and M.S. Smeltzer. 2006. Photothermal nanotherapeutics for selective killing of bacteria targeted with gold nanoparticles. Biophys. J. 90: 619-627. Zhang Y., F. Bao, J. Hu, S. Liang, Y. Zhang, G. Du, C. Zhang and Y. Chen. 2007. Antibacterial ligands and triterpenoids from Rostellularia procumbens. Planta Med. 73: 1596-1599. 